East African Medical Journal Vol. 77 No. 12 December 2000

GENITOURINARY PROLAPSE AND JOINT HYPERMOBILITY IN ETHIOPIAN WOMEN

K. Kiros, MD, Department of Gynaecology and Obstetrics, D. H. Mariam, PhD, MD, Department of Community of Health and D. Zemenfes, MD, Department of

Gynaecology and Obstetrics, Addis Ababa University, P.O. Box 1176, Addis Ababa, Ethiopia.

Request for reprints to: Dr. D. H. Mariam, P.O. Box 11950, Addis Ababa, Ethiopia.

\title{
GENITOURINARY PROLAPSE AND JOINT HYPERMOBILITY IN ETHIOPIAN WOMEN
}

\author{
K. KIROS, D. H. MARIAM and D. ZEMENFES
}

\begin{abstract}
Objectives: To assess the relationship between genitourinary prolapse (GUP) and joint hyper-mobility (JHM).

Design: Double-blind cross-sectional survey.

Setting: Adigrat hospital, northern Ethiopia, which serves as a referral centre for about one million people.

Patients: Two hundred and nine women were examined for joint hyper-mobility using the modified Carter-Wilkinson criteria. In addition, each patient was examined for genitourinary prolapse by a gynaecologist who was blind to the evaluation of JHM.

Results: Joint hyper-mobility was found in 78 out of 209 women (37\%). Subjects with joint hyper-mobility had a high prevalence of second and third degree genitourinary prolapse (58/78 versus 75/131 with odds ratio of 2.17 and $95 \%$ confidence interval of 1.12 - 4.23). Those subjects with age above 35 years were significantly more likely to have GUP than those less than or equal to age 35 years $(102 / 133$ versus $31 / 76$ with odds ratio of 4.78 and $95 \%$ confidence interval of $2.47-9.27$ ). In addition, a significant number of women with GUP had stress incontinence (68/133 versus 8/ 76 with odds ratio of 8.89 and $95 \%$ confidence interval of $3.73-211.94$ ).

Conclusion: The high prevalence of GUP in women with JHM suggests connective tissue abnormalities which may explain the unusually high prevalence of GUP in relatively young and low parity Ethiopian women besides the socio-economic and cultural factors. This implies that joint hyper-mobility may serve as a clinical marker for patients at risk of developing GUP.
\end{abstract}

\section{INTRODUCTION}

Pelvic organ relaxation results from injury of the supportive structures, most often through the tearing and attenuating forces first encountered during child birth. This may be later amplified by ageing(1). Obstetric trauma has long been thought to be the most important factor in the pathogenesis of genitourinary prolapse. This results through stretching and dehiscence of the ligaments and partial denervation of the pelvic floor muscles(2). However, there is considerable individual variability in the predisposition to genitourinary prolapse. Young nulliparous women occasionally develop genitourinary prolapse, whereas some multiparous women bear many children with no clinically significant pelvic relaxation(3). In our daily clinical practice it is not uncommon to see relatively young and sometimes nulliparous patients suffering from genitourinary prolapse. This clinical observation casts doubt on the traditional belief that obstetric factors and ageing are the only pathogenetic factors in this condition.
Norton has suggested that child birth, oestrogen deficiency, chronic intra-abdominal pressure and neurologic injury play important roles in women who are predisposed to genital prolapse. Such predisposition may be caused by something as simple as poor nutrition or as complex as an autosomal dominant genetic abnormality with variable penetrance(3). Norton et al(14) have found a significant association between joint hyper-mobility and genital prolapse and have concluded that this association suggests an underlying connective tissue disorder as one aetiology for pelvic relaxation and joint hyper-mobility. Thus, they have proposed such an association to be used as a useful clinical marker for future genetic studies to determine the genetic basis of genital prolapse(4). Such a clinical marker would be useful in following the natural history of genital prolapse and in studies of potential preventive measures such as episiotomy during vaginal birth or closure of the cul-de-sac and use of permanent suture support of the vaginal apex at the time of hysterectomy. 
Therefore, from the above suggestion and from clinical observations, one can hypothesise that, in addition to child birth injury, there must be some additional socio-economic and genetic factors that play some role in the frequent occurrence of genitourinary prolapse in relatively young Ethiopian women. Such a hypothesis entails an investigation for the possible association of joint hypermobility with genitourinary prolapse. If there is a clinically significant association between these factors, joint hypermobility can be considered as a clinical marker of those women at risk. This will then serve for devising some preventive measures against the occurrence of genitourinary prolapse.

The objective of the study was to determine whether joint hyper-mobility is associated with genital prolapse and to see whether congenital weakness of the supportive structure of the pelvic organs has a role to play in the common occurrence of genitourinary prolapse in relatively young Ethiopian women.

\section{MATERIALS AND METHODS}

The data for this study came from a double-blind crosssectional survey of all women who were attending Adigrat Hospital, Gynaecology outpatient department from July 1995 to February 1996. Adigrat Hospital is a referral hospital for one million people of the Eastern Tigray Zone (in northern Ethiopia). Referred patients also come from other neighbouring zones of the region. Most of the patients attending this hospital are of low socio-economic status. Excluding patients who were pregnant, in puerperium and those known to have connective tissue disorder, all patients who came with gynaecological complaints during the study period were included. Accordingly, 209 women were eligible to be included in the present study. With a precision of $5 \%$ and a $95 \%$ confidence interval, the sample size for this study was calculated to be about 200 patients.

A research protocol was reviewed and approved by the regional health bureau before being implemented. All subjects were informed about the purpose of the study and gave informed consent before participation. A data collection format was prepared which included factors that may influence joint mobility or genital prolapse: age, parity, history of straining with bowel movements, oestrogen replacement therapy, arthritis, steroid use and past surgical procedure. There were also items in the questionnaire that probed the subjects on symptoms of genitourinary prolapse. The response was entered in a preprepared format by the researchers.

In addition, each patient was evaluated for genitourinary prolapse by a gynaecologist (the principal investigator) and for joint hyper-mobility, using the modified Carter-Wilkinson criteria(5) by the hospital physician. This was a double blind study because the gynaecologist was blind to the results of the joint mobility evaluation and the physician to the gynaecological assessment. In addition, the gynaecologist was not involved in observing for joint hyper-mobility.

Pelvic relaxation was defined as grade $\mathrm{O}$ (no descent), grade 1 (descent toward the introitus), grade 2 (at the introitus), or grade 3 (beyond the introitus) and classified in the standing and straining positions for cystocele, rectocele and uterine or vault prolapse. Stress incontinence was elicited in the standing position while the subject, whose bladder was full, coughed. Under those conditions, stress incontinence was recorded either as present or absent.
With regard to joint mobility, subjects were identified as having hyper-mobile joint if two of the following three criteria were met: (i) passive opposition of one or both thumbs to the volar aspect of the forearm; (ii) passive hyperextension of one or both fifth digits to greater than 55 degrees from the horizontal or; (iii) active hyperextension of one or both elbows to greater than 190 degrees. This scale has been validated by studies published in the rheumatology literature and is widely used to grade joint hyper-mobility in the general population(4-6).

The collected data were entered into a computer using the Epi Info 6 software for analysis. The difference between the hyper-mobile and normal groups were evaluated by the $\chi 2$ statistics with $p$ value less than 0.05 considered as significant.

\section{RESULTS}

Two hundred and nine patients were included in the study. Sixty seven per cent of the women in the study sample were rural residents. Thirty seven per cent had joint hyper-mobility, whereas $63 \%$ had second and third degree genitourinary prolapse. Descent above the introitus, rectocele and enterocele were difficult to grade exactly and we analysed only as second and third degree GUP. Some of the mean characteristics of the study sample are shown in Table 1.

Table 1

Mean characteristics of study sample, northern Ethiopia

\begin{tabular}{lcccccr}
\hline Characteristic & \multicolumn{2}{c}{ No prolapse } & \multicolumn{2}{c}{ With prolapse } & \multicolumn{2}{c}{ Total } \\
\cline { 2 - 7 } & Mean & Range & Mean & Range & Mean & Range \\
\hline Age (years) & 32.54 & $18-53$ & 43.7 & $17-78$ & 39.6 & $17-78$ \\
Parity & 3.1 & $0-11$ & 5.2 & $0-15$ & 4.4 & $0-15$ \\
BMI & 19.25 & $12-28$ & 18.16 & $13-25$ & 18.56 & $12-28$ \\
\hline
\end{tabular}

Joint hyper-mobility was found to be more common in the relatively younger age group ( $43 \%$ in less than 35 years of age compared to $34 \%$ in those aged 35 years and above). However, this difference was not statistically significant $\left(\mathrm{OR}=0.67\right.$ with $95 \% \mathrm{CI}$ of $0.36-1.25\left[\chi^{2}=\right.$ 15.1 with $\mathrm{p}>0.1]$ ). The average parity of the subjects was 4.4 (with range of 0 to 15 ) and $53 \%$ were para 4 or less. As shown in Table 2, parity did not seem to have a significant influence on the prevalence of joint hyper-mobility, even though $48 \%$ of those with parity less than 4 had joint hyper-mobility.

\section{Table 2}

Parity and joint hyper-mobility, northern Ethiopia

\begin{tabular}{lccccccc}
\hline \multicolumn{9}{c}{ JHM } & & & & \\
Parity & No & Yes & Total & Or & $95 \%$ CI & $\chi 2$ & P value \\
\hline$\leq 4$ & 68 & 42 & 110 & 0.97 & $0.79-1.20$ & 0.02 & $<0.8980$ \\
$>4$ & 63 & 36 & 99 & & & & \\
\hline Total & 131 & 78 & 209 & & & \\
\hline
\end{tabular}


Even though about $41 \%$ of those below the age of 35 years had genitourinary prolapse, the prevalence of genitourinary prolapse seemed to increase with age (Table 3). Similarly, GUP seemed to be unusually high in women with low parity (Table 4), even though a significantly higher number of those with multiparity had genitourinary prolapse.

Table 3

Association between age and prolapse, northern Ethiopia

\begin{tabular}{lrrrrrrr} 
& \multicolumn{2}{c}{ Prolapse } & & & & & \\
Age & No & Yes & Total & OR & $95 \%$ CI & $\chi 2$ & P value \\
\hline$\leq 35$ & 45 & 31 & 76 & 4.78 & $2.47-9.27$ & 25.4 & $<0.001$ \\
$35+$ & 31 & 102 & 133 & & & & \\
\hline Total & 76 & 133 & 209 & & & & \\
\hline
\end{tabular}

Table 4

Association between parity and genitourinary prolapse, northern Ethiopia

\begin{tabular}{lccc}
\hline Parity & Having GUP & $\%$ & Total \\
\hline 0 & 5 & 31.2 & 16 \\
$1-2$ & 19 & 44.2 & 43 \\
$3-4$ & 29 & 56.9 & 51 \\
$>4$ & 80 & 80.8 & 99 \\
\hline Total & 133 & 65.6 & 209 \\
\hline
\end{tabular}

Table 5

Joint hyper-mobility and genitourinary prolapse, northern Ethiopia

\begin{tabular}{lrrrrrrr}
\hline & $\begin{array}{r}\text { No } \\
\text { GUP }\end{array}$ & $\begin{array}{r}\text { with } \\
\text { GUP }\end{array}$ & Total & $\begin{array}{l}\text { Odds } \\
\text { ratio }\end{array}$ & $95 \%$ CI & $\chi 2$ & P value \\
\hline No JHM & 20 & 58 & 78 & $\begin{array}{c}2.17 \\
-\end{array}$ & $1.20-4.23$ & 5.47 & 0.0194 \\
With JHM & 56 & 75 & 131 & - & & \\
\hline Total & 76 & 133 & 209 & - & \multicolumn{2}{l}{-} & \\
\hline
\end{tabular}

Table 6

Association between stress incontinence and prolapse, northern Ethiopia

\begin{tabular}{|c|c|c|c|c|c|c|c|}
\hline \multirow[b]{2}{*}{ Stress } & \multicolumn{2}{|c|}{ Prolapse } & \multirow[b]{2}{*}{ Total } & \multirow[b]{2}{*}{ OR } & \multirow[b]{2}{*}{$95 \% \mathrm{CI}$} & \multirow[b]{2}{*}{$\chi^{2}$} & \multirow[b]{2}{*}{$P$ value } \\
\hline & No & Yes & & & & & \\
\hline No & 68 & 65 & 76 & 8.89 & $3.73-21.94$ & 32.7 & $<0.001$ \\
\hline Yes & 8 & 68 & 133 & - & - & & \\
\hline Total & 76 & 133 & 209 & - & - & & \\
\hline
\end{tabular}

A significant number of women with joint hypermobility (JHM) had genitourinary prolapse (GUP) (58 out of 78 versus 75 out of 131 with odds ratio of 2.17 and $95 \%$ CI of $1.2-4.23\left[\chi^{2}=5.47\right.$ with $\left.p<0.02\right]$ ) (Table 5). In Table 6 , a significant number of those with prolapse had stress incontinence ( 68 out of 133 versus 8 out of 76 with odds ratio of 8.89 and $95 \% \mathrm{CI}$ of $3.7321 .94\left[\chi^{2}=32.72\right.$ with $\mathrm{p}<0.0001])$.

\section{DISCUSSION}

This study has found an association between joint hyper-mobility and genitourinary prolapse. Previous studies by Rawi et al(8) and by Norton(4) have also found $66 \%$ and $36 \%$ respectively of genitourinary prolapse cases as having joint hyper-mobility.

On the other hand, the prevalence of genitourinary prolapse in the present study was high compared to reports in western countries(14). It seems that genitourinary prolapse is common in Ethiopian women and it occurs in a relatively young age. The average age of patients with genitourinary prolapse in this study was 43.7 years (range 17-78 years). They are young compared with the commonly described cases elsewhere. This casts a doubt on the traditional belief that obstetric factors and ageing are the only pathogenetic factors for genitourinary prolapse. In our clinical practice we have seen a significant number of patients with genitourinary prolapse who are young and of low parity. This indicates that there must be, in addition to the obstetric factors and ageing, some other socio-economic or genetic factors that play a role in the pathogenesis of genitourinary prolapse.

Joint mobility was also found to be affected by age. Joint hyper-mobility was seen in $43 \%$ of those below the age of 35 years compared to only $34 \%$ of those above 35 years.

Theories regarding the aetiology of pelvic relaxation have focussed on the failure of the two supporting systems in the pelvis. Bird et al(9) have reported that joint laxity was greater during pregnancy than at four months postpartum and that the increase in laxity was even greater during gestation for the second pregnancy compared to the first. Fothergill(10) has theorised that pelvic relaxation develops as a result of inadequate suspension of the pelvic contents by their fascial and ligamentous connections, whereas Paramore(11) and Halban and Tandler (12) have argued that a defective muscular floor with its fascial connections was the important element in the aetiology. As suggested by Bonney(13), as early as 1917, both elements (ligamentous suspension and intact musculature) may be important in the suspension of the pelvic floor structures. Weakness of connective tissue in the pelvic fascia and ligaments may be responsible for the development of genitourinary prolapse, but the role of connective tissue in this condition has not been well studied. Nevertheless, currently the role of connective tissue is coming into the picture. Recent studies have demonstrated that the muscle and fascial components of the pelvic floor work together to provide satisfactory support for the pelvic viscera and their normal function. Collagen is the major structural protein in the ligamentous connective tissue. Collagen abnormalities are associated with a clinical spectrum of the findings ranging from 
relatively asymptomatic joint mobility to severe forms of Ehler-Danlos syndrome. Collagen undergoes marked remodeling and alterations in response to ageing, hormones, trauma and pregnancy, factors that have been suggested as contributing to the development of genital prolapse. During the perimenopausal period, a significant degree of loss of the collagen content of tissue (about 25\%) occurs, whilst elastin content remains unchanged. Such a reduction in collagen would result in a significant decrease in the mechanical strength of the tissue and thus lead to prolapse. Other investigators have suggested that the main problem in genitourinary prolapse is increased degradation of the collagen with a decrease in the tissues mechanical strength. There is increasing synthesis of new collagen and this newly formed collagen is degraded in preference to older material. Because increased collagenolytic activity appears to cause genitourinary prolapse, research aimed at inhibiting collagenolytic activity promises therapeutic possibilities(14).

In conclusion, this study has shown a high prevalence of genitourinary prolapse and a statistically significant association between joint hyper-mobility and genitourinary prolapse. This may indicate the presence of underlying connective tissue abnormalities besides socio-economic and cultural factors. This implies that joint hyper-mobility may serve as a clinical marker for patients at risk of developing genital prolapse and some preventive measures can be taken based on its assessment. Developing such clinical markers would be useful for following the natural history of genitourinary prolapse and genetic studies.

\section{ACKNOWLEDGEMENTS}

This study would not have been undertaken without the support of the administration and the staff of Adigrat Hospital. In addition, those patients and their families who participated in the study are duly acknowledged for their full collaboration.

\section{REFERENCES}

1. Jones, C.S., Kamm, M.A., Henry, M.M. and Hudson, C.N. Bowel dysfunction: a pathogenetic factor in uterovaginal prolapse and urinary stress incontinence. Brit. J. Obstet. Gynaec. 1994; 110:147- 152.

2. Nicholas, C. and Randall, C. Vaginal Surgery. Williams and Wilkins, Baltimore, 1976.

3. Norton, P.A. Pelvic Floor Disorders: The Role of Facia and Ligaments. Clin. Obstet. Gynaec. 1993; 36:926-938.

4. Norton, P.A., Baker, J.E., Sharp, H.C. and Warenski, J.C. Genitourinary prolapse and joint hypermobility in women. J. Obstet. Gynaec. 1995; 85:225 - 228.

5. Beighton, P., Solomon, L., \& Soskone, C. Articular mobility in an African population. Ann. Rheum. Dis. 1973; 32:413 - 418.

6. Kirk, J., Ansell, B. and Bywaters, L. The hypermobility syndrome: Musculoskeletal complaints associated with generalized joint hypermobility. Ann. Rheum. Dis. 1967; 26:419 - 425.

7. Jesse, E., Owen, D. and Sher, K. The benign hypermobile joint syndrome. Arth. Rheum. 1980; 23:1053 - 1056.

8. Al-Rawi, Z.S. and Al-Rawi, Z.T. Joint hypermobility in women with genital prolapse. Lancet. 1982; 1439- 1441.

9. Bird, H., Calguneri, M. and Wright, V. Changes in joint laxity during pregnancy. Ann. Rheum. Dis. 1981; 40:209 - 210

10. Fothergill, W. On the pathology and the operative treatment of displacements of the pelvic viscera.J. Obstet. Gynaec. 1907;13:410 - 419.

11. Paramore, R. The supports in chief of the female pelvic viscera. $J$. Obstet. Gynaec. 1908; 13:391 - 409.

12. Halban, J. and Tandler, J. Anatomic and etiologic der genital prolapse beim. Weim, Germany; Weilhelm Braumueller, 1907.

13. Bonney, V. Principles that should underlie all operations for prolapse. J. Obstet. Gynaec. 1934; 41:669-683.

14. Linda Cardozo. Prolapse. Dewhurst's text book of Obstetrics and Gynaecology for postgraduates. 1995; 642-652.

\section{Book Review}

A Compiled Research Reference Book (1965 - 2000), (Ed) Shija J. K., Health Education Unit, Ministry of Health, Dar es Salaam, Tanzania, 2000; pages 320

I found the book to be extremely interesting from many points of view. For example, the study on hospital incidences of congenital anomalies was a spectacular epidemiological study of disease incidence which is the key to determining how many paediatric surgeons are needed in a particular country. In another place a mention is made about the future of paediatric surgery so not only individual paediatric surgical disorders are covered but also issues related to the field of paediatric surgery itself, particularly in Tanzania. Most of all however, this book is a chronicle to the author's career and commitment to building the field of paediatric surgery in Tanzania and contributing to it's welfare in the continent of Africa. So few of us have such an opportunity and I congratulate the author for what he has achieved

James A. O'Neill, Jr. M.D, J.C. Foshee Distinguished Professor of Surgery, Chairman, Section of Surgical, Sciences, Vanderbilt University, Nashville, Tennessee, U.S.A.

August 22, 2000 